\title{
Differential impact of child sexual abuse and family history of suicidal behavior in high-risk suicidal patients
}

Leandro N. Grendas, Sasha M. Rojas, Demián E. Rodante, Soledad Puppo, Patricia Vidjen, Alicia Portela \& Federico M. Daray

To cite this article: Leandro N. Grendas, Sasha M. Rojas, Demián E. Rodante, Soledad Puppo, Patricia Vidjen, Alicia Portela \& Federico M. Daray (2019): Differential impact of child sexual abuse and family history of suicidal behavior in high-risk suicidal patients, Archives of Suicide Research, DOI: $10.1080 / 13811118.2019 .1592040$

To link to this article: https://doi.org/10.1080/13811118.2019.1592040

Accepted author version posted online: 07

Apr 2019.

Submit your article to this journal $₫$

山 Article views: 4

View Crossmark data ¿ 


\section{Differential impact of child sexual abuse and family history of suicidal behavior in high-risk suicidal patients}

Leandro N.GRENDAS MD ${ }^{\mathrm{a}, \mathrm{b}}$, Sasha M. $\operatorname{ROJAS}^{\mathrm{c}}$,Demián E. RODANTE, MD ${ }^{\mathrm{a}, \mathrm{d}}$,Soledad PUPPO, MD ${ }^{\mathrm{e}}$,Patricia VIDJEN, MD ${ }^{\mathrm{f}}$,Alicia PORTELA, MD ${ }^{\mathrm{f}}$,Federico M. DARAY, MD, MSc, $\mathrm{PhD}{ }^{\mathrm{a}, \mathrm{d}, \mathrm{g}}$

${ }^{\text {a }}$ Institute of Pharmacology, School of Medicine, University of Buenos Aires, 2155 Paraguay, Buenos Aires, Argentina, C1121ABG.

b “Dr. Teodoro Álvarez” General Hospital. Dr. Juan Felipe Aranguren 2701, Buenos Aires, , Argentina, C1406FWY.

${ }^{\mathrm{c}}$ Department of Psychological Science, University of Arkansas, Fayetteville, Arkansas, USA, 72701.

d "Dr. Braulio A. Moyano" Neuropsychiatric Hospital, Brandsen 2570, Buenos Aires, Argentina, C1287ABJ.

e “José de San Martín” Hospital, Av. Córdoba 2351, Buenos Aires, Argentina, C1120AAR.

f، José Tiburcio Borda” Hospital, Dr. Ramon Carrillo 375, Buenos Aires, Argentina, C1275AHG.

g National Scientific and Technical Research Council (CONICET), Godoy Cruz 2290, Buenos Aires, Argentina, C1425FQB.

Submitted to: Archives of Suicide Research, USUI-2018-0166-R1, February 2019 [224 word abstract, 3502 word text, 57 references, 3 tables] 
Conflict of Interest: No author a potential for conflicts of interest.

*Correspondence to: Dr. F.M. Daray, Instituto de Farmacología, Facultad de Medicina, Universidad de Buenos Aires. Paraguay 2155, piso 9, C1121ABG, Ciudad de Buenos Aires, Argentina. Tel (5411) 5950-9500 (interno: 2161). Email:fdaray@hotmail.com

Role of Funding Source: Federico Manuel Daray is a research member of CONICET. This study was funded by a grant from Ministry of Science, Technology and Productive Innovation of Argentina (PIDC-2012-0064). The funding source had no involvement in study design; in the collection, analysis, and interpretation of data; in the writing of the report; and in the decision to submit the paper for publication

Disclosures: No author or immediate family member has financial relationships with commercial entities that might appear to represent a potential for conflicts of interest. All authors have approved the final article.

Acknowledgment: The authors want to gratefully acknowledge the study participants for their collaboration, the nursing staff and field teams in each Hospital.

\section{Abstract}

Objectives: The current study aimed to compare suicide-related variables as a function of 1) family history of suicidal behavior and 2) child sexual abuse among patients hospitalized for a suicide attempt or active suicidal ideation. Family history of suicidal behavior and child sexual abuse were examined independently and in combination as a diathesis for a high-risk suicidal 
phenotype. Method: A multicenter cross-sectional study was designed to compare data obtained from 292 patients hospitalized for suicidal behavior. Demographic and clinical variables were compared among group 1 (patients who reported both family history of suicidal behavior and child sexual abuse), group 2 (patients who reported only family history of suicidal behavior), group 3 (patients who reported only child sexual abuse) and group 4 (patients who did not report family history of suicidal behavior or childhood sexual abuse). A multinomial logistic regression was used to examine suicide-related variables associated with each group and to compare differences between groups. Results: Group 1 and 3 endorsed a higher number of previous suicide attempts and were more likely to be younger at the first suicide attempt as compared to group 4. Group differences remained after adjustment in a multinomial regression model. Conclusions: The current findings suggest that child sexual abuse may be more strongly related to suicide risk among high risk patients as compared to family history of suicidal behavior.

Keywords: family history of suicidal behavior; child sexual abuse; suicidal behavior

\section{Differential impact of child sexual abuse and family history of suicidal behavior in high-risk suicidal patients}

\section{Introduction}

The World Health Organization (WHO) estimated 788,000 suicide deaths occurred worldwide in 2015, resulting in an annual global age-standardized suicide rate of 10.7 per 100,000 persons (WHO). Suicide only captures a part of the problem; given the rates of suicide attempts and suicidal ideation are even higher. For every death by suicide, there are 10 to 20 times more individuals who attempt suicide, and the cross-national lifetime prevalence of suicidal ideation, plans, and suicide attempts is $9.2 \%, 3.1 \%$, and $2.7 \%$, respectively (M. K. Nock et al., 2008). 
Suicide is preventable and the WHO has declared reducing suicide-related mortality as a global imperative (WHO, 2015). For this reason, there are growing efforts focused on reducing incidences of suicide. Suicide prevention strategies can be improved by identifying groups of individuals that are at high risk for suicide. To this end, suicidal ideation and suicide attempts have been identified as a strong predictor of more severe and potentially fatal suicidal behavior (Klonsky, May, \& Saffer, 2016). Taken together, identification of individuals who endorse high risk for suicidal behavior represents an important opportunity to intervene.

Suicidal behavior is a complex problem and several explanatory models have been proposed to understand the progression to suicidal behavior and suicide, including the stressdiathesis model of suicidal behavior (Mann, 2003; Mann, Waternaux, Haas, \& Malone, 1999). This framework indicates there is an interaction between multiple factors and stress that elevates risk for suicidal behavior (Mann et al., 1999). Specifically, suicidal behavior is thought to be the result of an interaction between a diathesis or independent predisposition for suicide risk and a stressor (exacerbation of a mental disorder or an acute psychosocial crisis). The term diathesis includes heritable factors, including family history of suicidal behavior, and early life factors, such as child sexual abuse, which may increase risk for suicidal behavior (Mann, 2003; Mann et al., 1999; van Heeringen \& Mann, 2014). Other theoretical models that focus on the transition from suicidal ideation to suicidal behavior, such as the Integrated Motivational-Volitional Model, also recognize the importance of these diathesis factors, in providing the backdrop for the development of suicidal behavior (O'Connor, 2011; O'Connor \& Kirtley, 2018; O'Connor \& Portzky, 2018; O’Connor, 2011).

Previous studies highlight the association between many of these components of the diathesis and future suicidal behavior (e.g., (Roy \& Janal, 2005; Turecki \& Brent, 2016). Individuals engage in suicidal behavior across different timeframes, which may be influenced by 
the interaction of predisposition risk factors and the degree of experienced stress. Thus, if an individual poses multiple predisposition risk factors they are considered highly vulnerable, and minor stressors may lead to suicide risk. This theoretical framework presupposes additivity, indicating that the interaction between factors within the diathesis and stress contributes to risk for suicidal behavior (van Heeringen, 2012).

Although there is evidence that family history of suicidal behavior and childhood sexual abuse increase vulnerability for suicidal behavior (Daray et al., 2016; Gould, Fisher, Parides, Flory, \& Shaffer, 1996; Joiner et al., 2007; Rodante et al., 2016; Simon, 2011), family history of suicidal behavior and childhood sexual abuse have not been studied independently in patients at high risk for suicide. The current study aims to address this gap in the literature by comparing suicide-related factors as a function of two important components of the diathesis for suicide risk: 1) family history of suicidal behavior and 2) childhood sexual abuse among a diverse high-risk suicidal patient sample.

\section{Method}

\subsection{Study Design}

The present study used a cross-sectional design to compare baseline data obtained as part of a larger multicentre study conducted in Buenos Aires, Argentina. Patients were recruited from three different hospitals: the "Dr. Braulio A. Moyano" neuropsychiatric hospital, the "Dr. José T. Borda" hospital and the Hospital de Clínicas "José de San Martin". All hospitals serve a large urban catchment area in Buenos Aires and predominantly treat lower-income, uninsured patients. The study procedures were approved by the Institutional Review Board of all three hospitals.

\subsection{Participants}

Participants were patients admitted to the psychiatry emergency department of one of the three different hospitals for active suicidal ideation or a recent suicide attempt. All patients were 
between the ages of 18 and 65 years $(36.83 \pm 12.56) ; 68$ patients identified as male and 222 identified as female. The majority of the sample was Argentine (89.27\%), while other patients reported their country of origin as Paraguay (4.16\%), Peru (1.38\%), Bolivia (1.04\%), Colombia (1.04\%), Uruguay (1.04\%), Chile (0.69\%), and other $(1.38 \%)$.

\subsection{Procedure}

Patients were recruited between August 2012 and May 2017, and those who were consecutively admitted for active suicidal ideation or a recent suicide attempt were evaluated to determine eligibility for the the current study. Interviews were conducted by three psychiatrists with a minimum of 5 years of experience in clinical psychiatry (LG, SP and AP). All psychiatrists received additional training in the semi-structured interviews administered as part of the study protocol. Suicidal ideation was defined as any current self-reported thought of engaging in suicide-related behavior (Matthew K Nock, 2014). A suicide attempt was defined as a potentially self-injurious behavior with a nonfatal outcome, for which there was evidence (either explicit or implicit) that the person intended at some (non-zero) level to kill him or herself

(Silverman, Berman, Sanddal, O'Carroll P, \& Joiner, 2007). Initial evaluation was performed to determine if patients met inclusion criteria: a) age between 18 and 65 years, b) admission for active suicidal ideation or a suicide attempt, and c) provided written informed consent. Patients were excluded if: a) unable to respond autonomously (i.e., due to sedative effects of medication or language limitations) and b) were transferred to another institution within 48 hours. Patients who met inclusion criteria were given a complete description of the study and invited to participate. Each patient who agreed to participate provided written informed consent.

\subsection{Measures}


Each participant underwent a semi-structured interview with a psychiatrist from the research team, which included questions about clinical and demographic variables as described previously (Grendas et al., 2017; Teti et al., 2014).

2.4.1. Patient history of suicidal behavior. Patient history of suicide attempts, age of first attempt, and hospitalizations due to suicidal behavior were assessed during this interview. The Columbia-Suicide Severity Rating Scale (C-SSRS) (Posner et al., 2011) was used to obtain additional details regarding lifetime and most recent suicidal behavior.

2.4.2. Patient history of child sexual abuse. Patient history of child sexual abuse, defined as any sexual activity with a child, prior to the age of 18 years, where consent was not or cannot be given (Andrews, Corry, Slade, Issakidis, \& Swanston, 2004; Berliner \& Elliot, 2002), was assessed during the semi-structured interview. Sexual abuse was coded dichotomously as yes or no. Patients who did not report a history of child sexual abuse received a code indicating no history of child sexual abuse.

2.4.3. Family history of suicidal behavior. Family history of suicidal behavior was assessed during the semi-structured interview. Family history of suicidal behavior was defined as suicide attempts or suicide among first and/or second-degree relatives of the patients. Patients who did not report a family history of suicidal behavior received a code indicating no family history of suicidal behavior.

2.4.4. Psychopathology. The Mini International Neuropsychiatric Interview (MINI) (Bobes, 1998) and the Structured Clinical Interview for DSM-IV Axis II Disorders (SCID-II) (Villar Garcia et al., 1995) were used to obtain diagnostic information. Additional information specific to symptomology was obtained from self-report inventories including, Barratt Impulsiveness Scales (BIS-11) (Lopez, Cetkovich-Bakmas, Lischinsky, Alvarez Prado, \& Torrente, 2012), 
Buss-Durkee Hostility Inventory (BDHI) (Oquendo. et al., 2001), and the Beck's Hopelessness Scale (BHS) (Mikulic, Cassullo, Crespi, \& Marconi, 2009).

\subsection{Data Analytic Approach}

Categorical measures are reported as frequencies or percentages, and continuous measures are reported as means \pm standard deviations $(S D)$. The sample was divided into 4 groups: [1] patients who reported both family history of suicidal behavior and child sexual abuse $(n=68)$, [2] patients who reported family history of suicidal behavior but not child sexual abuse $(n=71)$, [3] patients who reported childhood sexual abuse but not family history of suicidal behavior $(n=57)$, and [4] patients who did not report either family history of suicidal behavior and child sexual abuse $(n=94)$. A univariate multinomial logistic regression was used to examine the variables associated with each group and to compare differences between groups. The associations between variables were quantified with odds ratios $(\mathrm{OR})$ and respective $95 \%$ confidence intervals $(\mathrm{CI})$. A multivariate multinomial regression model was performed to determine the variables independently associated to each group and to compare groups. Independent variables were included stepwise from the least to the most significant in preliminary testing. Specifically, significant variables were individually entered into the univariate analysis. Group 4 was used as control group in both analyses. The threshold of statistical significance for the multinomial model was set at $p$ adjusted by the Bonferroni method $(p<0.01)$.Statistical analyzes were performed using STATA 13.0.

\section{Results}

3.1 Sample description. A total of 323 patients who met eligibility criteria entered the emergency department during the study period, and $90 \%$ gave their consent to participate. Demographic and clinical variables specific to the groups are presented in Table 1. Overall, patients were similar in terms of their demographic and clinical characteristics. However, the 
prevalence of borderline personality disorder was significantly higher in all groups as compared to group 4. Among all four groups, patients were predominately female, had an average age between 34 - 39 years, and approximately $25 \%$ of the patients were married or cohabitating.

\subsection{Comparison between the study groups}

Participants in groups 1, 2, and 3 were more likely to be female as compared to participants in group $4(\mathrm{OR}=8.17-95 \% \mathrm{CI}=3.00-22.23 ; \mathrm{OR}=2.2-95 \% \mathrm{CI}=1.11-4.46 ; \mathrm{OR}=3-95 \% \mathrm{CI}=$ 1.37-6.77, respectively). Participants in groups 1, 2, and 3 were also younger at the first suicide attempt $(\mathrm{OR}=0.90-95 \% \mathrm{CI}=0.94-0.98 ; \mathrm{OR}=0.98-95 \% \mathrm{CI}=0.96-0.99 ; \mathrm{OR}=0.96-95 \% \mathrm{CI}=$ 0.93-0.98, respectively) and reported more previous suicide attempts $(\mathrm{OR}=1.17-95 \% \mathrm{CI}=1.04-$ $1.31 ; \mathrm{OR}=1.15-95 \% \mathrm{CI}=1.02-1.29 ; \mathrm{OR}=1.15-95 \% \mathrm{CI}=1.02-1.29$, respectively) as compared to participants in group 4. Participants in group 1 were more likely to report higher lethality in their suicide attempt as compared to participants in group $4(\mathrm{OR}=1.36-95 \% \mathrm{CI}=1.02-1.81)$. Participantss in group 2 reported lower impulsivity as compared to participants in group 4 (BIS total score; $\mathrm{OR}=0.97-95 \% \mathrm{CI}=0.95-0.99)$. Please refer to Table 2 for results from the univariate multinomial logistic regression.

\subsection{Multivariate multinomial logistic regression}

The resulting model (Table 3 ) confirmed that groups 1, 2 and 3 were more likely to be female than those in group $4(\mathrm{OR}=7.57-95 \% \mathrm{CI}=2.71-21.13 ; \mathrm{OR}=2.27-95 \% \mathrm{CI}=1.11-4.64$; $\mathrm{OR}=2.80-95 \% \mathrm{CI}=1.21-6.50$, respectively). Only group 1 and 3 had a higher number of previous suicide attempts as compared to group $4(\mathrm{OR}=2.84-95 \% \mathrm{CI}=1.31-6.17 ; \mathrm{OR}=3.53$ $95 \% \mathrm{CI}=1.53-8.16$, respectively). Participants in group 1 and 3 were more likely to be younger at first suicide attempt $(\mathrm{OR}=0.96-95 \% \mathrm{CI}=0.93-0.98 ; \mathrm{OR}=0.95-95 \% \mathrm{CI}=0.92-0.98$, respectively) as compared to group 4.

\section{Discussion}


Mann et al. (1999) proposed a stress-diathesis model based on the integration of neurobiology and psychopathology, which still informs current research and theoretical models in suicidology (Mann et al., 1999). In this model, suicidal behavior is determined not merely by a stressor (e.g., psychiatric illness) but also by a diathesis or predisposition (e.g., family history of suicidal behavior). The model was based on findings from clinical research studies comparing patients with and without suicidal behavior. However, there are also important differences to decipher among patients with suicidal ideation or a suicide attempt. For example, in clinical practice it is important to determine which patients are at high risk for suicidal behavior and how to intervene accordingly. For this reason, the framework provided by the diathesis-stress model may help determine levels of risk among suicidal patients. In the current study we examined two important components of the diathesis in the stress-diathesis model: 1) family history of suicidal behavior and 2) childhood sexual abuse (Mann, 2003; Mann \& Haghighi, 2010; Mann et al., 1999). The goal of this study was to obtain more specific findings related to these important risk factors in the diathesis for suicidal behavior among a large patient sample with different psychiatric diagnoses. Primary findings suggest suicidal patients with a history of childhood sexual abuse were more likely to endorse other suicide-related variables. It is possible that childhood sexual abuse is more likely to determine a high-risk phenotype of suicidal patients as compared to family history of suicidal behavior.

Previous studies evidence family history of suicidal behavior increases risk for suicide attempts (Brent et al., 2002; Gould et al., 1996; Melhem et al., 2007; Roy \& Janal, 2005; B. S. Runeson, 1998), and suicide (Gould et al., 1996; Hawton \& van Heeringen, 2009; B. Runeson \& Asberg, 2003; Simon, 2011), independent of psychopathology (Gould et al., 1996; Melhem et al., 2007; Simon, 2011). There is also an established association between the number of suicide attempts and family history of suicidal behavior (Rodante et al., 2016). There is considerably less 
work aimed at evaluating the unique association of family history of suicidal behavior and different suicide-risk characteristics. In the current study, patients who reported family history of suicidal behavior, but not childhood sexual abuse, did not significantly report more suicide-risk characteristics (e.g., more previous suicide attempts, early age of the first suicide attempt) as compared to patients who did not report family history of suicidal behavior. On the contrary, Roy and colleagues (2004) found that suicidal patients with a family history of suicidal behavior made their first suicide attempt at an earlier age as compared to patients without family history of suicidal behavior (Roy, 2004). Roy et al. (2004) studied family history of suicidal behavior among a sample of abstinent substance-dependent patients, which differs from the diverse clinical sample in the current study. Also noteworthy, in Roy et al. (2004), childhood sexual abuse was not explored. Although family history of suicidal behavior has been associated with the number of previous suicide attempts, the current findings do not support this association among a highrisk sample of suicidal patients.

Child sexual abuse is a severe form of childhood trauma that increases risk for lifetime suicide attempts (Afifi et al., 2016; Hoertel et al., 2015; Joiner et al., 2007; Maniglio, 2011; Soloff, Lynch, \& Kelly, 2002; Turecki \& Brent, 2016). In the present study, child sexual abuse was examined instead of childhood trauma, given its relevance in the diathesis for suicidal behavior (Brodsky, 2016). In the current study, patients who reported child sexual abuse were more likely to also report other suicide-risk characteristics as compared to patients who did not report childhood sexual abuse. Specifically, there was a significant association between childhood sexual abuse and number of previous suicide attempts, which has been observed in previous studies (Daray et al., 2016; Joiner et al., 2007). There was also a significant association between childhood sexual abuse and age at first suicide attempt, independent of psychopathology, which is similar to previous findings (Hoertel et al., 2015). According to the 
current findings and the diathesis-stress model for suicidal behavior, the impact of childhood sexual abuse should be carefully assessed and considered when conceptualizing baseline and acute risk for suicidal behavior among patients.

The findings of the present study are consistent with previous work indicating patients suffering for early traumatic experiences and family history of suicidal behavior endorse an earlier age onset of a first suicide attempt and more suicide attempts across their life, as compared with patients without either factor (Carballo et al., 2008; Lopez-Castroman et al., 2012; Roy, 2011). Lopez-Castroman et al. (2012) found that among a large sample of patients hospitalized for a suicide attempt, patients with family history of suicidal behavior and childhood trauma were younger at their first suicide attempt, and made more frequent, severe and violent attempts when compared with subjects with only one or with neither of these two risk factor (Lopez-Castroman et al., 2012). In another retrospective study among patients with bipolar disorder, Carballo et al. (2008) found patients with family history of suicidal behavior and childhood abuse were significantly younger at first suicide attempt as compared to subjects without these risk factors. Patients did not, however, differ significantly from those with only one of these factors, and patients with one or two factors had significantly more previous suicide attempts as compared to patients without any factor (Carballo et al., 2008). In the present study, we replicated and extended these observations among a sample of patients with different diagnoses (MDD; schizophrenia and BD). The present study was also the first to examine family history of suicidal behavior and childhood sexual abuse individually and in combination. Therefore, the present findings extend previous work by indicating previous childhood sexual abuse may be more strongly related to other suicide-related factors among high-risk suicidal patients as compared to a family history of suicidal behavior. 
Childhood sexual abuse was examined in the current study as opposed to early traumatic experiences. Importantly, distress and posttraumatic stress symptoms that may follow childhood sexual abuse can be addressed via evidence-based treatments, including Dialectical Behavior Therapy, which is also an evidence based treatment suicidal behavior (Bohus et al., 2013; Bohus, Dyer, Priebe, Kruger, \& Steil, 2011; DeCou, Comtois, \& Landes, 2019; Steil, Dyer, Priebe, Kleindienst, \& Bohus, 2011). Future research is needed to see how childhood sexual abuse is related to suicide risk following evidence based treatment that directly targets the distress specific to the previous trauma. As theoretical models for suicidal behavior continue to refine (Mann et al., 1999; O'Connor, 2011), our understanding of the impact of modifiable risk factors within the diathesis for suicide behavior should improve.

No differences regarding psychopathology were found across the different groups. In part, this may be explained by the high-risk nature of the patient sample. Specifically patients endorsed higher scores in hopelessness, impulsivity and hostility as compared to the cut off points proposed by the scale validation (Mikulic et al., 2009; Oquendo et al., 2001; Oquendo. et al., 2001). These patterns lead to a ceiling effect, which limited our ability to detect differences among groups (Cramer \& Howitt, 2004). The prevalence of borderline personality disorder was higher in all groups as compared with group 4. Indeed, childhood sexual abuse and psychopathology of relatives with suicidal behavior are factors that have been associated with the development of borderline personality disorder (Boucher et al., 2017; de Aquino Ferreira, Queiroz Pereira, Neri Benevides, \& Aguiar Melo, 2018; Infurna et al., 2016; Leichsenring, Leibing, Kruse, New, \& Leweke, 2011). Substance use disorder and affective disorders did not differentiate groups. Future work is needed to investigate the impact of mental health diagnoses and psychological symptoms on the relations observed in this study. For example, future work may consider potential mechanisms that underlie the pathway between childhood sexual abuse 
and 1) age of first suicide attempt and 2) frequency of suicide attempts. This study has several strengths. For example, the current findings suggest childhood sexual abuse was associated with suicide-related variables indicating greater suicide risk among patients hospitalized for suicidal thoughts and behaviors, as opposed to comparing suicidal patients with healthy controls. As such, these findings allow us to observe that childhood sexual abuse is associated with variables indicating severity among a high-risk sample. It is clinically relevant to recognize that childhood sexual abuse had more weight in determining the severity of the suicidal phenotype as compared to family history of suicidal behavior. These findings should be considered for clinical assessment of suicide risk. Overall, these results further shed light to the importance of assessing and treating childhood sexual abuse. Future prospective studies that examine the impact of evidence-based interventions aimed at addressing childhood sexual abuse and suicide risk in tandem are now needed.

Limitations should be considered when interpreting the study findings. First, the primary variables of interest, family history of suicidal behavior and childhood sexual abuse were determined by a larger semi-structured interview that included questions specific to other clinical and demographic data. The structure of the interview did not include questions about other childhood trauma. The method for assessing the studied variables is similar to methods used across multiple studies and other studies that have demonstrated high agreement between a series of similar semi structured screening questions and validated scales for these factors (Brodsky et al., 2008; Goodwin, Beautrais, \& Fergusson, 2004; Roy, 2004; B. S. Runeson, 1998). Nonetheless, future work would benefit from exploring how other childhood traumas related to the suicide-related factors studied in this study. The patients included in the current study were hospitalized for current suicidal thoughts and behaviors, as such the findings should generalize to 
patients of similar severity. In addition the majority of patients were women, which further limits generalizability of the current findings.

\section{References}

Afifi, T. O., Taillieu, T., Zamorski, M. A., Turner, S., Cheung, K., \& Sareen, J. (2016). Association of Child Abuse Exposure With Suicidal Ideation, Suicide Plans, and Suicide Attempts in Military Personnel and the General Population in Canada. JAMA Psychiatry, 73(3), 229-238. doi: 10.1001/jamapsychiatry.2015.2732

Andrews, G., Corry, J., Slade, T., Issakidis, C., \& Swanston, H. (2004). Child Sexual Abuse. In M. Ezzati, A. D. Lopez, A. Rodgers \& C. J. L. Murray (Eds.), Comparative Quantification of Health Risks (Vol. 2, pp. 1851-1940). Geneva: World Health Organization.

Berliner, L., \& Elliot, D. (2002). Sexual abuse of children. In J. E. B. Myers, L. Berliner, J. Briere, C. T. Hendrix, C. Jenny \& T. A. Reid (Eds.), The APSAC handbook on child maltreatment (2nd ed.). Los Angeles: SAGE.

Bobes, J. (1998). A Spanish validation study of the mini international neuropsychiatric interview. European Psychiatry, 13, 198s-199s.

Bohus, M., Dyer, A. S., Priebe, K., Kruger, A., Kleindienst, N., Schmahl, C., . . Steil, R. (2013). Dialectical behaviour therapy for post-traumatic stress disorder after childhood sexual abuse in patients with and without borderline personality disorder: a randomised controlled trial. Psychother Psychosom, 82(4), 221-233. doi: 10.1159/000348451

Bohus, M., Dyer, A. S., Priebe, K., Kruger, A., \& Steil, R. (2011). [Dialectical behavior therapy for posttraumatic stress disorder in survivors of childhood sexual abuse]. Psychother Psychosom Med Psychol, 61(3-4), 140-147. doi: 10.1055/s-0030-1263162

Boucher, M. E., Pugliese, J., Allard-Chapais, C., Lecours, S., Ahoundova, L., Chouinard, R., \& Gaham, S. (2017). Parent-child relationship associated with the development of borderline personality disorder: A systematic review. Personal Ment Health, 11(4), 229255. doi: 10.1002/pmh.1385

Brent, D. A., Oquendo, M., Birmaher, B., Greenhill, L., Kolko, D., Stanley, B., . . Mann, J. J. (2002). Familial pathways to early-onset suicide attempt: risk for suicidal behavior in offspring of mood-disordered suicide attempters. Arch Gen Psychiatry, 59(9), 801-807. doi: yoa10184 [pii]

Brodsky, B. S. (2016). Early Childhood Environment and Genetic Interactions: the Diathesis for Suicidal Behavior. Curr Psychiatry Rep, 18(9), 86. doi: 10.1007/s11920-016-0716-Z

Brodsky, B. S., Mann, J. J., Stanley, B., Tin, A., Oquendo, M., Birmaher, B., . . Brent, D. (2008). Familial transmission of suicidal behavior: factors mediating the relationship between childhood abuse and offspring suicide attempts. J Clin Psychiatry, 69(4), 584596.

Carballo, J. J., Harkavy-Friedman, J., Burke, A. K., Sher, L., Baca-Garcia, E., Sullivan, G. M., . . . Oquendo, M. A. (2008). Family history of suicidal behavior and early traumatic 
experiences: additive effect on suicidality and course of bipolar illness? J Affect Disord, 109(1-2), 57-63. doi: 10.1016/j.jad.2007.12.225

Cramer, D., \& Howitt, D. L. (2004). The Sage dictionary of statistics: a practical resource for students in the social sciences: Sage.

Daray, F. M., Rojas, S. M., Bridges, A. J., Badour, C. L., Grendas, L., Rodante, D., . . Rebok, F. (2016). The independent effects of child sexual abuse and impulsivity on lifetime suicide attempts among female patients. Child Abuse Negl, 58, 91-98. doi:

10.1016/j.chiabu.2016.06.011

de Aquino Ferreira, L. F., Queiroz Pereira, F. H., Neri Benevides, A. M. L., \& Aguiar Melo, M. C. (2018). Borderline personality disorder and sexual abuse: A systematic review.

Psychiatry Res, 262, 70-77. doi: 10.1016/j.psychres.2018.01.043

DeCou, C. R., Comtois, K. A., \& Landes, S. J. (2019). Dialectical Behavior Therapy Is Effective for the Treatment of Suicidal Behavior: A Meta-Analysis. Behav Ther, 50(1), 60-72. doi: 10.1016/j.beth.2018.03.009

Goodwin, R. D., Beautrais, A. L., \& Fergusson, D. M. (2004). Familial transmission of suicidal ideation and suicide attempts: evidence from a general population sample. Psychiatry Res, 126(2), 159-165. doi: 10.1016/j.psychres.2004.02.010

Gould, M. S., Fisher, P., Parides, M., Flory, M., \& Shaffer, D. (1996). Psychosocial risk factors of child and adolescent completed suicide. Arch Gen Psychiatry, 53(12), 1155-1162.

Grendas, L., Rodante, D., Rojas, S., Puppo, S., Vidjen, P., Lado, G., . . . Daray, F. M. (2017). Determinants of mental and physical health-related quality of life among patients hospitalized for suicidal behavior. Psychiatry Res, 257, 56-60. doi:

10.1016/j.psychres.2017.07.029

Hawton, K., \& van Heeringen, K. (2009). Suicide. Lancet, 373(9672), 1372-1381. doi: S01406736(09)60372-X [pii] 10.1016/S0140-6736(09)60372-X

Hoertel, N., Franco, S., Wall, M. M., Oquendo, M. A., Wang, S., Limosin, F., \& Blanco, C. (2015). Childhood maltreatment and risk of suicide attempt: a nationally representative study. J Clin Psychiatry, 76(7), 916-923; quiz 923. doi: 10.4088/JCP.14m09420

Infurna, M. R., Fuchs, A., Fischer-Waldschmidt, G., Reichl, C., Holz, B., Resch, F., . . Kaess, M. (2016). Parents' childhood experiences of bonding and parental psychopathology predict borderline personality disorder during adolescence in offspring. Psychiatry Res, 246, 373-378. doi: 10.1016/j.psychres.2016.10.013

Joiner, T. E., Jr., Sachs-Ericsson, N. J., Wingate, L. R., Brown, J. S., Anestis, M. D., \& Selby, E. A. (2007). Childhood physical and sexual abuse and lifetime number of suicide attempts: a persistent and theoretically important relationship. Behav Res Ther, 45(3), 539-547. doi: 10.1016/j.brat.2006.04.007

Klonsky, E. D., May, A. M., \& Saffer, B. Y. (2016). Suicide, Suicide Attempts, and Suicidal Ideation. Annu Rev Clin Psychol, 12, 307-330. doi: 10.1146/annurev-clinpsy-021815093204

Leichsenring, F., Leibing, E., Kruse, J., New, A. S., \& Leweke, F. (2011). Borderline personality disorder. Lancet, 377(9759), 74-84. doi: 10.1016/s0140-6736(10)61422-5

Lopez-Castroman, J., Jaussent, I., Beziat, S., Genty, C., Olie, E., de Leon-Martinez, V., . . . Guillaume, S. (2012). Suicidal phenotypes associated with family history of suicidal behavior and early traumatic experiences. J Affect Disord, 142(1-3), 193-199. doi: 10.1016/j.jad.2012.04.025 
Lopez, P. L., Cetkovich-Bakmas, M., Lischinsky, A., Alvarez Prado, D., \& Torrente, F. (2012). [Psychometric properties of the Barratt Impulsiveness Scale in a sample of the city of Buenos Aires]. Vertex, 23(102), 85-91.

Maniglio, R. (2011). The role of child sexual abuse in the etiology of suicide and non-suicidal self-injury. Acta Psychiatr Scand, 124(1), 30-41. doi: 10.1111/j.1600-0447.2010.01612.x

Mann, J. J. (2003). Neurobiology of suicidal behaviour. Nat Rev Neurosci, 4(10), 819-828. doi: $10.1038 / \mathrm{nrn} 1220$

Mann, J. J., \& Haghighi, F. (2010). Genes and environment: multiple pathways to psychopathology. Biol Psychiatry, 68(5), 403-404. doi: 10.1016/j.biopsych.2010.07.006

Mann, J. J., Waternaux, C., Haas, G. L., \& Malone, K. M. (1999). Toward a clinical model of suicidal behavior in psychiatric patients. Am J Psychiatry, 156(2), 181-189. doi: 10.1176/ajp.156.2.181

Melhem, N. M., Brent, D. A., Ziegler, M., Iyengar, S., Kolko, D., Oquendo, M., . . Mann, J. J. (2007). Familial pathways to early-onset suicidal behavior: familial and individual antecedents of suicidal behavior. Am J Psychiatry, 164(9), 1364-1370. doi: 164/9/1364 [pii]10.1176/appi.ajp.2007.06091522

Mikulic, I. M., Cassullo, G. L., Crespi, M. C., \& Marconi, A. (2009). Beck hopelessness scale BHS (A. Beck, 1974): psychometric study and standardization or argentinian adaptation. Anuario de Investigaciones 16, 365-373.

Nock, M. K. (2014). The Oxford handbook of suicide and self-injury: Oxford University Press.

Nock, M. K., Borges, G., Bromet, E. J., Alonso, J., Angermeyer, M., Beautrais, A., ... Williams, D. (2008). Cross-national prevalence and risk factors for suicidal ideation, plans and attempts. Br J Psychiatry, 192(2), 98-105. doi: 10.1192/bjp.bp.107.040113

O'Connor, R. C. (2011). The integrated motivational-volitional model of suicidal behavior. Crisis, 32(6), 295-298. doi: 10.1027/0227-5910/a000120

O'Connor, R. C., \& Kirtley, O. J. (2018). The integrated motivational-volitional model of suicidal behaviour. Philos Trans R Soc Lond B Biol Sci, 373(1754). doi: 10.1098/rstb.2017.0268

O'Connor, R. C., \& Portzky, G. (2018). The relationship between entrapment and suicidal behavior through the lens of the integrated motivational-volitional model of suicidal behavior. Curr Opin Psychol, 22, 12-17. doi: 10.1016/j.copsyc.2017.07.021

O’Connor, R. C. (2011). Towards an integrated motivational-volitional model of suicidal behaviour. International handbook of suicide prevention: Research, policy and practice, 1, 181-198.

Oquendo, M. A., Baca García, E., Graver, R., Morales, M., Montalbán, V., \& Mann, J. J. (2001). Spanish adaptation of the Barratt Impulsiveness Scale (BIS-11). Eur J Psychiatry(15), 147-155.

Oquendo., Graver, R., Baca-García, E., Morales, M., Montalbán, V., \& Mann, J. J. (2001). Spanish Adaptation of Buss-Durkee Hostility Inventory (BDHI). Eur J Psychiatry, 15(101-112).

Posner, K., Brown, G. K., Stanley, B., Brent, D. A., Yershova, K. V., Oquendo, M. A., . . Mann, J. J. (2011). The Columbia-Suicide Severity Rating Scale: initial validity and internal consistency findings from three multisite studies with adolescents and adults. Am J Psychiatry, 168(12), 1266-1277. doi: 10.1176/appi.ajp.2011.10111704

Rodante, D., Rojas, S. M., Feldner, M. T., Dutton, C., Rebok, F., Teti, G. L., . . Daray, F. M. (2016). Differences between female suicidal patients with family history of suicide attempt and family history of completed suicide. Compr Psychiatry, 70, 25-31. doi: 10.1016/j.comppsych.2016.06.006 
Roy, A. (2004). Family history of suicidal behavior and earlier onset of suicidal behavior. Psychiatry Res, 129(2), 217-219. doi: 10.1016/j.psychres.2004.08.002

Roy, A. (2011). Combination of family history of suicidal behavior and childhood trauma may represent correlate of increased suicide risk. J Affect Disord, 130(1-2), 205-208. doi: 10.1016/j.jad.2010.09.022

Roy, A., \& Janal, M. (2005). Family history of suicide, female sex, and childhood trauma: separate or interacting risk factors for attempts at suicide? Acta Psychiatr Scand, 112(5), 367-371. doi: 10.1111/j.1600-0447.2005.00647.x

Runeson, B., \& Asberg, M. (2003). Family history of suicide among suicide victims. Am J Psychiatry, 160(8), 1525-1526. doi: 10.1176/appi.ajp.160.8.1525

Runeson, B. S. (1998). History of suicidal behaviour in the families of young suicides. Acta Psychiatr Scand, 98(6), 497-501.

Silverman, M. M., Berman, A. L., Sanddal, N. D., O'Carroll P, W., \& Joiner, T. E. (2007). Rebuilding the tower of Babel: a revised nomenclature for the study of suicide and suicidal behaviors. Part 2: Suicide-related ideations, communications, and behaviors. Suicide Life Threat Behav, 37(3), 264-277. doi: 10.1521/suli.2007.37.3.264

Simon, R. (2011). Preventing patient suicide: clinical assessment and management (First ed.). Arlington: American Psychiatric Publishing.

Soloff, P. H., Lynch, K. G., \& Kelly, T. M. (2002). Childhood abuse as a risk factor for suicidal behavior in borderline personality disorder. J Pers Disord, 16(3), 201-214.

Steil, R., Dyer, A., Priebe, K., Kleindienst, N., \& Bohus, M. (2011). Dialectical behavior therapy for posttraumatic stress disorder related to childhood sexual abuse: a pilot study of an intensive residential treatment program. J Trauma Stress, 24(1), 102-106. doi: $10.1002 /$ jts. 20617

Teti, G. L., Rebok, F., Grendas, L. N., Rodante, D., Fogola, A., \& Daray, F. M. (2014). [Patients hospitalized for suicidal ideation and suicide attempt in a Mental Health Hospital: Clinicodemographical features and 6-month follow-up]. Vertex, 25(115), 203-212.

Turecki, G., \& Brent, D. A. (2016). Suicide and suicidal behaviour. Lancet, 387(10024), 1227 1239. doi: 10.1016/s0140-6736(15)00234-2

van Heeringen, K. (2012). Stress-Diathesis Model of Suicidal Behavior. In Y. Dwivedi (Ed.), The Neurobiological Basis of Suicide. Boca Raton (FL): CRC Press/Taylor \& Francis Llc.

van Heeringen, K., \& Mann, J. J. (2014). The neurobiology of suicide. Lancet Psychiatry, 1(1), 63-72. doi: 10.1016/s2215-0366(14)70220-2

Villar Garcia, M., Perez Prieto, J. F., Hernandez Viadel, M., Renovell Farre, M., Leal Cercos, C., $\&$ Gomez Beneyto, M. (1995). [Preparation of a SCID-II-based diagnostic tool for personality disorders. Spanish version. Translation and adaptation]. Actas Luso Esp Neurol Psiquiatr Cienc Afines, 23(4), 178-183.

WHO. Available from: http://www.who.int/gho/mental_health/suicide_rates/en/.

WHO. (2015). Preventing suicide: A global imperative. 2014. URL: http://apps. who. int/iris/bitstream/10665/131056/1/9789241564779_eng.pdf. 
Table 1. Patient characteristics of the sample

\begin{tabular}{|c|c|c|c|c|}
\hline & $\begin{array}{c}\text { Group } 1 \\
\begin{array}{c}(\text { FHSB+CSA+) } \\
n=68\end{array}\end{array}$ & $\begin{array}{c}\text { Group2 } \\
\begin{array}{c}\text { (FHSB+ CSA-) } \\
n=71\end{array}\end{array}$ & $\begin{array}{c}\text { Group } 3 \\
\begin{array}{c}\text { (FHSB- CSA+) } \\
n=57\end{array}\end{array}$ & $\begin{array}{c}\text { Group } 4 \\
\text { (FHSB- CSA-) } \\
n=94\end{array}$ \\
\hline Socio-demographic & Mean (SD) & Mean $(S D)$ & Mean (SD) & $\operatorname{Mean}(S D)$ \\
\hline \multirow[t]{2}{*}{ Age } & $34.77(11.52)$ & $38.83(12.87)$ & $35.19(10.90)$ & $37.79(13.77)$ \\
\hline & $\mathrm{n}(\%)$ & $\mathrm{n}(\%)$ & $\mathrm{n}(\%)$ & $\mathrm{n}(\%)$ \\
\hline Female & $63(92.65)$ & $55(77.46)$ & $47(82.46)$ & $57(60.64)$ \\
\hline Married/cohabitating & $19(27.94)$ & $16(22.54)$ & $15(26.32)$ & $13(13.83)$ \\
\hline Suicidal behavior & $\mathrm{n}(\%)$ & $\mathrm{n}(\%)$ & $\mathrm{n}(\%)$ & $\mathrm{n}(\%)$ \\
\hline Previous SA & $55(80.88)$ & $49(69.01)$ & $47(82.46)$ & $53(56.38)$ \\
\hline \multirow{2}{*}{$\begin{array}{l}\text { Highly lethal SA } \\
\text { (index via C-SSRS) }\end{array}$} & $38(55.88)$ & $36(50.70)$ & $28(49.12)$ & $40(42.55)$ \\
\hline & Mean $(S D)$ & & Mean (SD) & Mean (SD) \\
\hline Age of first SA & $22.69(11.64)$ & $27.18(15.27)$ & $21.61(13.67)$ & $29.76(15.65)$ \\
\hline Diagnosis & $\mathrm{n}(\%)$ & $\mathrm{n}(\%)$ & $\mathrm{n}(\%)$ & $\mathrm{n}(\%)$ \\
\hline Affective disorder & $51(75)$ & $45(63.38)$ & $44(77.19)$ & $68(72.34)$ \\
\hline Schizophrenia and & & $18(25.35)$ & $9(15.79)$ & $18(19.15)$ \\
\hline \multicolumn{5}{|l|}{ related disorders } \\
\hline Other & $8(10.45)$ & $8(11.27)$ & $4(7.02)$ & $8(8.15)$ \\
\hline Co-occurring & $\mathrm{n}(\%)$ & $\mathrm{n}(\%)$ & $\mathrm{n}(\%)$ & $\mathrm{n}(\%)$ \\
\hline disorders & & & & \\
\hline BPD & $39(57.35)$ & $31(43.66)$ & $30(52,63)$ & $25(26.59)$ \\
\hline SAD & $6(8.82)$ & $11(15.49)$ & $8(14.04)$ & $18(19.15)$ \\
\hline Psychopathology & Mean $(S D)$ & $\operatorname{Mean}(S D)$ & $\operatorname{Mean}(S D)$ & $\operatorname{Mean}(S D)$ \\
\hline Impulsiveness (BIS) & $68.80(16.41)$ & $62.55(14.66)$ & $68.64(13.83)$ & $68.04(14.90)$ \\
\hline Hopelessness (BHS) & $9.94(5.09)$ & $9.47(4.38)$ & $9.56(4.68)$ & $9.98(4.72)$ \\
\hline
\end{tabular}


Note: $S D=$ standard deviation; $S A=$ suicide attempt; C-SSRS= Columbia-Suicide Severity Rating Scale; $\mathrm{BPD}=$ borderline personality disorder; $\mathrm{SAD}=$ substance abuse disorder; $\mathrm{BIS}=\mathrm{Barratt}$ Impulsiveness Scale; BHS= Beck Hopelessness Scale; BDHI= Buss-Durkee Hostility Inventory; FHSB: family history of suicidal behavior; CSA: child sexual abuse.

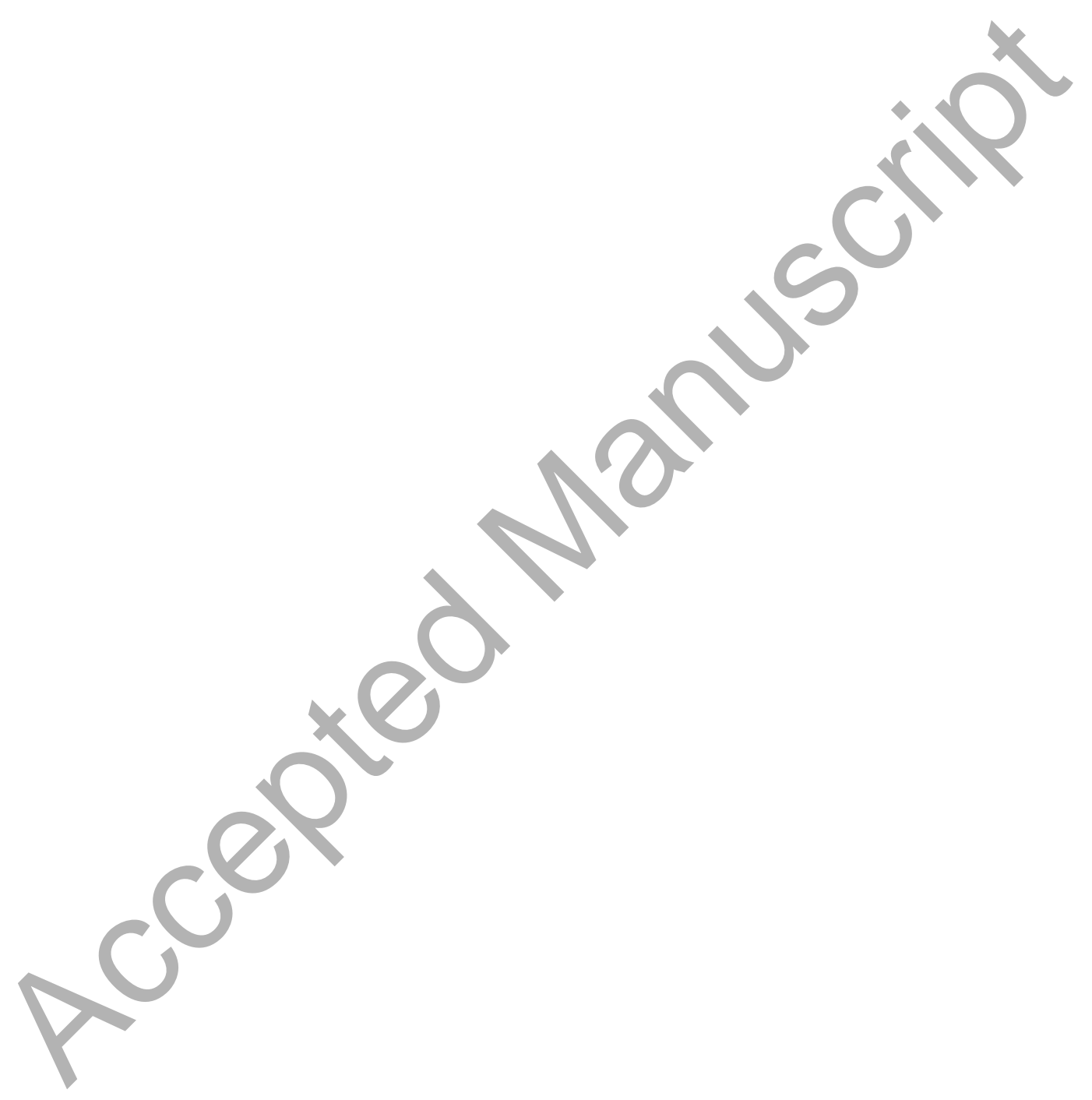


Table 2. Univariate multinomial logistic regression results comparing groups

\begin{tabular}{|c|c|c|c|}
\hline Group & $\mathrm{OR}$ & CI 95\% & $p$ \\
\hline \multicolumn{4}{|l|}{ Group $1(F H S B+C S A+)$} \\
\hline Female & 8.17 & $3.00-22.23$ & $<0.01$ \\
\hline Age & 0.98 & $0.95-1.00$ & 0.13 \\
\hline Previous SA & 1.17 & $1.04-1.31$ & $<0.01$ \\
\hline Age of first SA & 0.9 & $0.94-0.98$ & $<0.01$ \\
\hline Highly lethal SA & 1.36 & $1.02-1.81$ & 0.03 \\
\hline 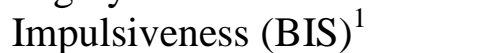 & 1 & $0.98-1.02$ & 0.75 \\
\hline Hopelessness (BHS) ${ }^{2}$ & 0.99 & $0.93-1.06$ & 0.95 \\
\hline Hostility (BDHI) ${ }^{3}$ & 1 & $0.97-1.04$ & 0.56 \\
\hline \multicolumn{4}{|l|}{ Group 2 (FHSB+CSA-) } \\
\hline Female & 2.2 & $1.11-4.46$ & 0.02 \\
\hline Age & 1 & $0.98-1.03$ & 0.60 \\
\hline Previous SA & 1.15 & $1.02-1.29$ & 0.04 \\
\hline Age of first SA & 0.98 & $0.96-0.99$ & $<0.01$ \\
\hline Highly lethal SA & 1.21 & $0.91-1.60$ & 0.18 \\
\hline Impulsiveness (BIS) ${ }^{1}$ & 0.97 & $0.95-0.99$ & 0.03 \\
\hline Hopelessness (BHS) ${ }^{2}$ & 0.97 & $0.91-1.04$ & 0.50 \\
\hline Hostility (BDHI) ${ }^{3}$ & 1 & $0.96-1.03$ & 0.93 \\
\hline \multicolumn{4}{|l|}{ Group 3 (FHSB- CSA+) } \\
\hline Female & & $1.37-6.77$ & $<0.01$ \\
\hline Age & & $0.95-1.009$ & 0.2 \\
\hline Previous SA & 1.15 & $1.02-1.29$ & 0.01 \\
\hline Age of first SA & 0.96 & $0.93-0.98$ & $<0.01$ \\
\hline Highly lethal SA & 1.15 & $0.85-1.55$ & 0.35 \\
\hline Impulsiveness (BIS) ${ }^{1}$ & 1 & $0.97-1.02$ & 0.81 \\
\hline Hopelessness (BHS) ${ }^{2}$ & 0.98 & $0.91-1.05$ & 0.60 \\
\hline Hostility (BDHI) ${ }^{3}$ & 0.98 & $0.95-1.02$ & 0.55 \\
\hline
\end{tabular}

Note: Group 4(FHSB- CSA-)was used as a reference. FHSB: family history of suicidal behavior; CSA: child sexual abuse. 
Table 3. Multiple regression model results comparing differences between groups

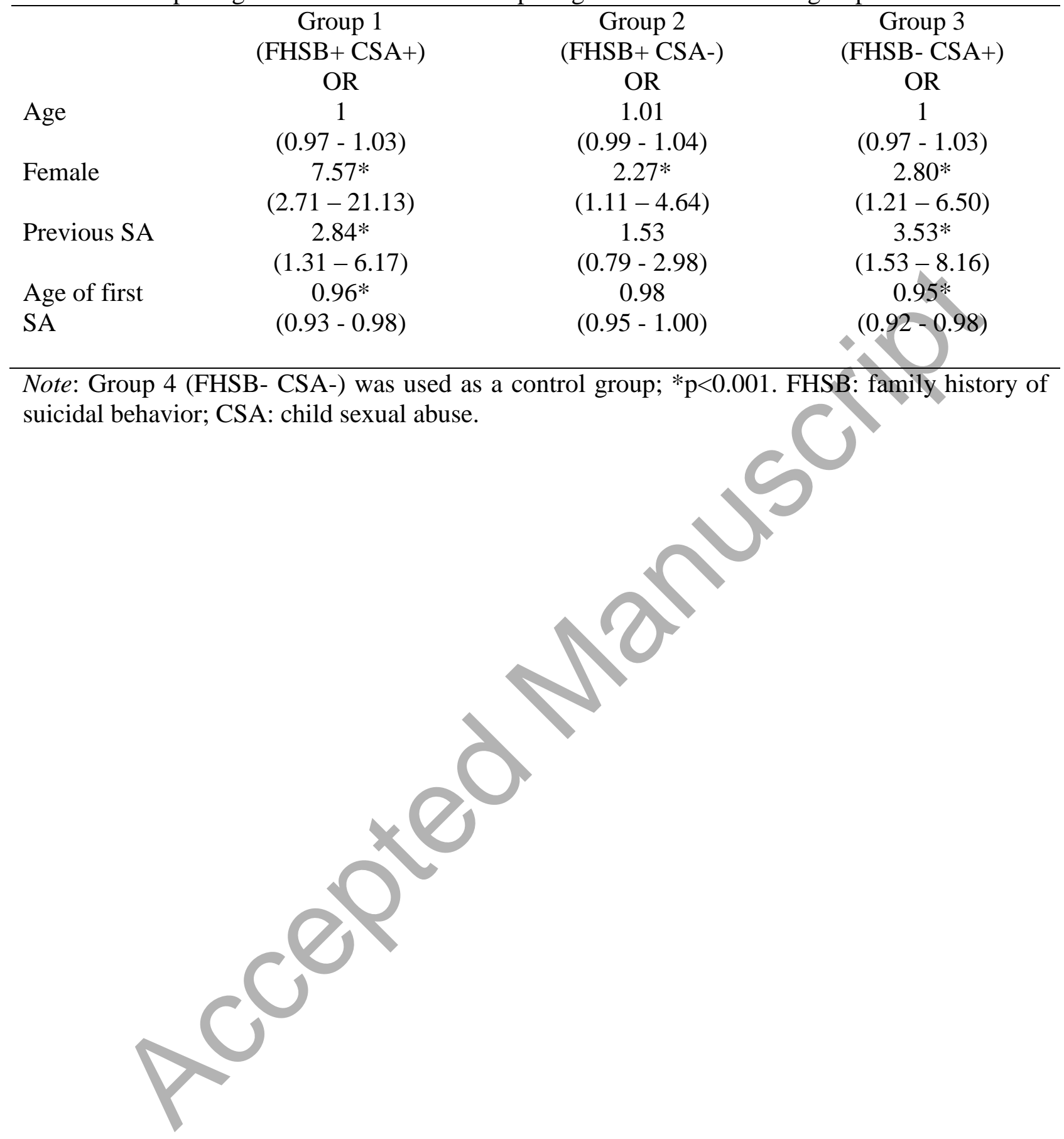

